\title{
PERAN TEKNOLOGI INFORMASI \\ DALAM MENGINFORMASIKAN DATA WISATA AIR TERJUN DI WEBSITE DINAS PARIWISATA SETIAP KABUPATEN DI BALI
}

\author{
Ayu Aprilyana Kusuma Dewi \\ Email: aprilyana.beklencipss15@gmail.com
}

\begin{abstract}
The information on waterfall tourism destination provided in the tourism office website of each regency in Bali is still limited. There is a need to manage them in a database which can be monitored regularly and can be informed to the public through the tourism office website of each regency in Bali. Some regencies in Bali that have had the data collection of waterfall tourism destinations were involved to gain the data. The purpose of this study is to analyze the tourism office website of each regency of Bali, in order to be able to utilize and maximize the presentation of information in an appropriate, easy and updated manner. Besides, it can let the public know the waterfall which is untouched by many tourists. The research methodology carried out includes several stages, namely system analysis, literature study, problem identification, goal setting, information needs analysis, data inventory, presentation of results and evaluation. The conclusion of this study is that three regencies in Bali have used a website, four districts in Bali already have a website but do not have information on tourist areas, and one Kelungkung Regency does not have a website. The expected result of this study is the utilization of tourism office websites of each regency in Bali. So that it can introduce tourism in each region to visiting tourists and can improve the performance of the tourism department and increase government foreign exchange earnings.
\end{abstract}

Keywords: Information Technology, Waterfall Tourism, Website, Tourism Office

\section{Abstrak}

Sampai saat ini informasi wisata air terjun dalam setiap website milik Dinas Pariwisata per kabupaten di Bali masih memiliki kekurangan dalam menginformasikan wisata setiap daerah kepada wisatawan. Maka dibutuhkan pengelolaan dalam suatu basis data yang secara periode dapat dimonitor dan disampaikan secara luas melalui media teknologi informasi dalam website Dinas Pariwisata setiap kabupaten di Bali. Untuk menganalisis teknologi informasi ini diambil beberapa kabupaten yang 
telah menerapkan data wisata air terjun secara maksimal dan belum maksimal. Tujuan dari penelitian ini adalah menganalisis website Dinas Pariwisata setiap kabupaten di Bali, agar dapat memanfaatkan dan memaksimalkan penyajian informasi secara tepat, mudah dan update. Hal lain yang didapatkan yaitu dapat memperkenalkan wisata air terjun yang masih belum terjamah oleh banyak wisatawan. Metodologi penelitian yang dilakukan meliputi beberapa tahapan yaitu analisis sistem, studi literatur, identifikasi masalah, penentuan tujuan, analisis kebutuhan informasi, inventarisasi data, penyajian hasil dan evaluasi.

Simpulan penelitian ini adalah tiga kabupaten di Bali telah memanfaatkan situs website, empat kabupaten di Bali sudah memiliki website namun tidak memiliki informasi daerah wisata, dan Kabupaten Kelungkung tidak memiliki situs website. Hasil akhir yang diharapkan pada penelitian ini adalah pemanfaatan website milik Dinas Pariwisata setiap kabupaten dalam memberikan informasi mengenai wisata air terjun yang dimiliki setiap daerah di Bali, sehingga dapat memperkenalkan wisata disetiap daerah ke wisatawan yang berkunjung serta dapat memajukan kinerja Dinas Pariwisata dan meningkatkan devisa pemasukan pemerintah.

Kata Kunci: Teknologi Informasi, Wisata Air Terjun, Website, Dinas Pariwisata

\section{Pendahuluan}

Perkembangan teknologi semakin berkembang seiring kebutuhan masyarakat akan informasi yang semakin berkembang pula. Perkembangan zaman serta teknologi yang menjadi penyebab kehidupan masyarakat ikut berubah. Untuk saat ini masyarakat berkeinginan dalam setiap pekerjaannya dapat dimudahkan, cepat dan tepat. Termasuk pula dalam hal bidang wisata yang informasinya sangat diperlukan oleh wisatawan maupun masyarakat umum khususnya mengenai informasi tentang wisata air terjun yang ada di setiap Kabupaten di Bali. Terdapat beberapa hal yang dapat dijadikan sebagai analisis dalam memaksimalkan kinerja Dinas Pariwisata disetiap kabupaten.

CBIS (Computer Based Information System) atau dalam Bahasa Indonesia biasa disebut dengan Sistem Informasi Bebasis Komputer yang 
merupakan sistem pengelolaan data menjadi sebuah informasi yang berkualitas dan dapat dipergunakan untuk suatu alat bantu dalam pengambilan keputusan. Sistem Informasi yang lebih akurat serta efektif, pada kenyataannya saling berhubungan yang dapat di istilahkan dengan sebutan "computer-based" atau dapat pula disebut dengan pengelolaan informasi berbasis komputer. Sistem Informasi yang "berbasis komputer" diartikan bahwa sebuah komputer memiliki peranan penting dalam sebuah sistem informasi.

Secara teori, penerapan sebuah Sistem Informasi memang tidak diharuskan menggunakan komputer dalam setiap kegiatannya. Tetapi dalam prakteknya tidak memungkinkan sistem informasi yang sangat kompleks tersebut berjalan dengan baik bila tidak menggunakan komputer. Website (situs web) merupakan kumpulan dari beberapa halaman situs yang biasanya terangkum dalam sebuah domain atau subdomain, yang berada dalam World Wide Web (WWW) di Internet. Selain itu website dapat digunakan untuk memberikan informasi yang berkualitas, tepat, cepat serta memiliki kemudahan dalam pengaksesan secara global [A].

Informasi merupakan data yang dapat diolah menjadi suatu bentuk yang berguna dan menjadi berarti untuk penerimanya. Kegunaan informasi adalah untuk mengurangi ketidakpastian didalam proses pengambilan keputusan mengenai suatu keadaan. Suatu informasi dapat dikatakan bernilai bila manfaat yang dihasilkan lebih efektif dibandingkan dengan biaya yang digunakan untuk mendapatkan informasi tersebut. Kualitas informasi sangat dipengaruhi atau ditentukan oleh beberapa hal yaitu: a. Relevan, b. Akurat, c. Tepat Waktu, d. Ekonomis, e. Efisien, f. Ketersediaan, g. Dapat Dipercaya dan h. Konsisten.

Internet merupakan jaringan komputer yang menghubungkan puluhan hingga milyaran komputer yang ada di seluruh dunia untuk dapat saling berkomunikasi serta dapat bertukar informasi baik dalam bidang 
pendidikan, institusi pendidikan, organisasi pemerintahan dan individual [B]. Internet sendiri memiliki sejarah yang sangat kompleks dan mencakup banyak aspek seperti teknologi, organisasi dan komunitas. Pengaruh internet tidak hanya terhadap bidang teknik komunikasi komputer saja tetapi dapat pula pada masalah sosial semisalnya dengan menggunakan alat-alat bantu online untuk mencapai bisnis elektronik (e-commerce), kepemilikan informasi dan interaksi dengan masyarakat umum. Website juga dapat diartikan sebagai suatu kumpulan halaman yang dapat menampilkan berbagai macam informasi berupa teks, data, gambar diam maupun bergerak, data animasi, suara, video ataupun gabungan dari keseluruhan, baik dalam bersifat statis maupun dinamis dalam membentuk satu rangkaian bangunan yang saling terkait. Website merupakan alamat (URL) yang berfungsi sebagai tempat penyimpanan data dan informasi dengan berdasarkan topik yang dipilih [C]. Tujuan penelitian ini adalah mengetahui peran teknologi dalam menginformasikan data wisata air terjun di website Dinas Pariwisata setiap kabupaten di Bali.

\section{Metode}

Untuk mendukung kemudahan akses dan berbagi informasi mengenai wisata air terjun, maka dibuat model skema konseptual untuk mengetahui informasi-informasi yang diperlukan sebagai rencana pengevaluasian dari website milik Dinas Pariwisata di setiap kabupaten di Bali seperti diperlihatkan pada Gambar 1. 


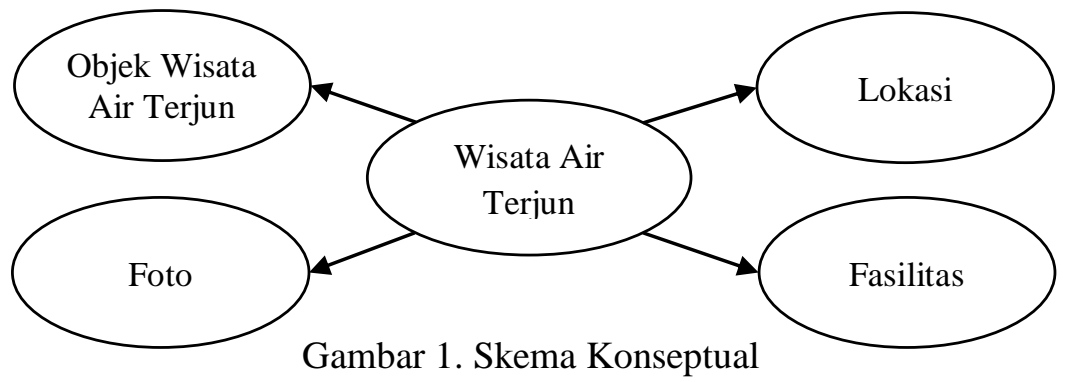

Skema konseptual telah diterapkan dibeberapa website Dinas Pariwisata, yaitu pada Kabupaten Buleleng, Kabupaten Karangasem dan Kabupaten Jembrana. Sedangkan untuk beberapa website Dinas Pawisata pada kabupaten lain masih belum menerapkannya. Maka perlu dijelaskan lebih terperinci pada konsep eksternal agar dapat membantu Dinas Pariwisata untuk memperbaiki dan memberikan informasi yang lebih lengkap dan bermanfaat.

\subsection{Metode Pengembangan Sistem}

Untuk mengembangkan suatu sistem informasi, digunakan suatu metodologi yang disebut metodologi pengembangan sistem. Metodologi adalah suatu proses standar yang diikuti oleh organisasi untuk melaksanakan seluruh langkah yang diperlukan untuk menganalisis, merancang, mengimplementasikan dan memelihara sistem informasi [D]. Pada tahapan ini setiap pihak Dinas Pariwisata dapat melakukan pengembangan sistem sesuai dengan keperluan yang nantinya bertujuan untuk memaksimalkan kinerja Dinas Pariwisata dalam memberikan informasi mengenai wisata air terjun disetiap daerah. 


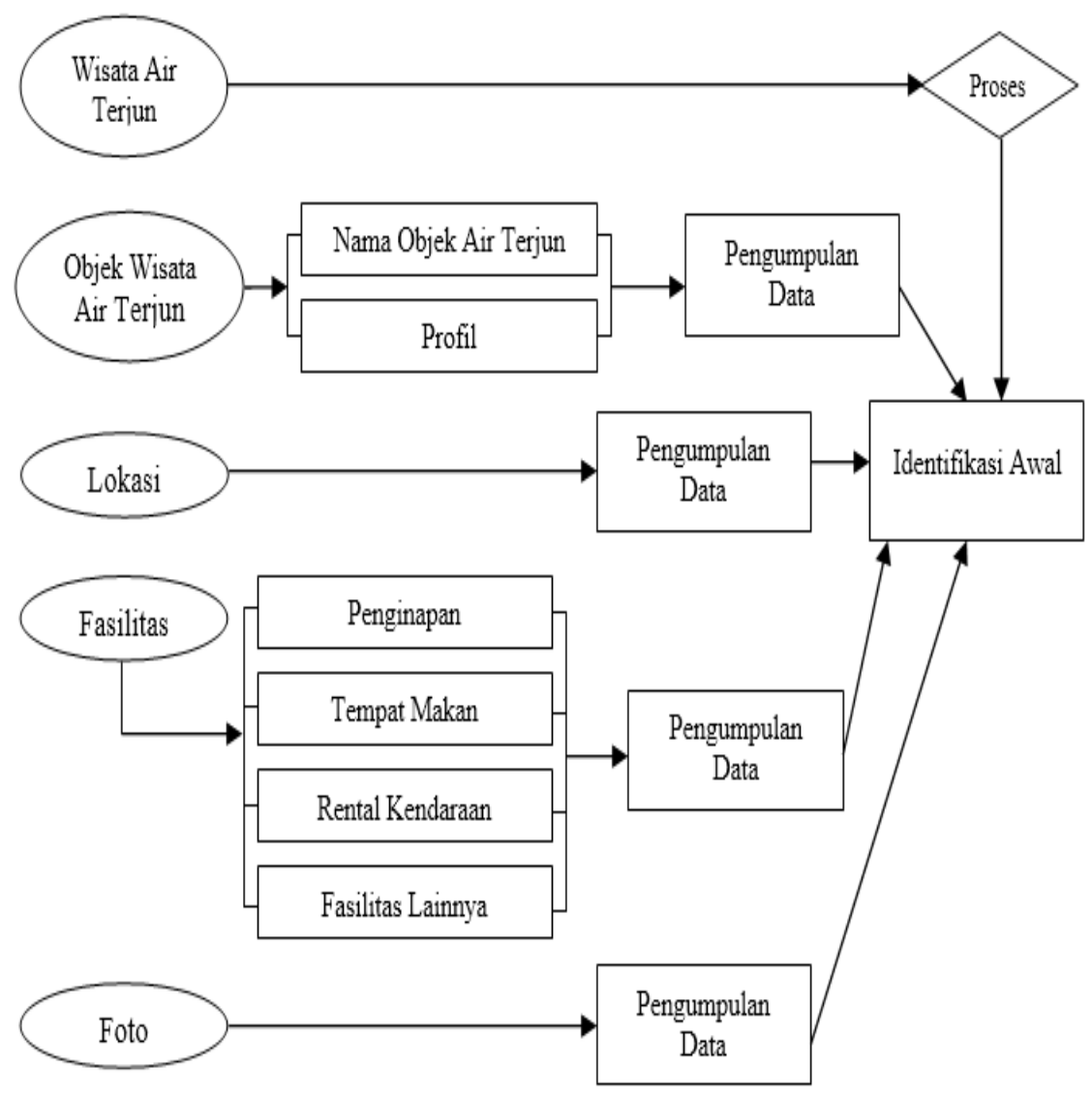

Gambar 2. Skema Konseptual Eksternal

\section{Hasil dan Pembahasan}

Dalam pengembangan sistem informasi wisata air terjun pada situs website Dinas Pariwisata kabupaten di Bali dapat memformulasikan sebuah sistem informasi yang menggunakan interprise pemrograman sehingga diharapkan kelak informasi mengenai wisata air terjun dan permasalahan lain dapat dengan mudah dan cepat divisualisasikan. Salah satu contoh visualisasi dari penjelasan itu dapat diambil pada situs website Dinas Pariwisata kabupaten Buleleng yang terdapat pada gambar 3. 


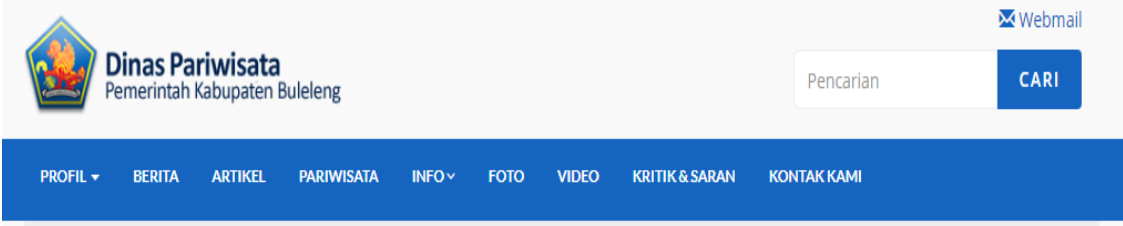

ผ Home > Pariwisata

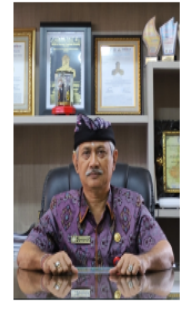

Ir. Nyoman Sutrisna, MM

\section{Pariwisata \\ Wisata Agro \\ Wisata Alam \\ Wisata Alam Flora - Fauna}

Gambar 3. Situs Website Dinas Pariwisata Kabupaten Buleleng

Informasi yang disajikan pada situs website diatas dapat diimplementasikan dengan menginformasikan mengenai jenis wisata di kabupaten tersebut, jenis wisata yang ada, fasilitas disekitar tempat wisata dan foto objek wisata yang dapat menarik wisatawan serta tercantumnya nama objek wisata air terjun yang telah ada disetiap daerah. Untuk mengetahui gambaran menu wisata air terjun dapat dilihat pada situs website atau contoh lain pada situs website milik Kabupaten Jembrana pada gambar 4.

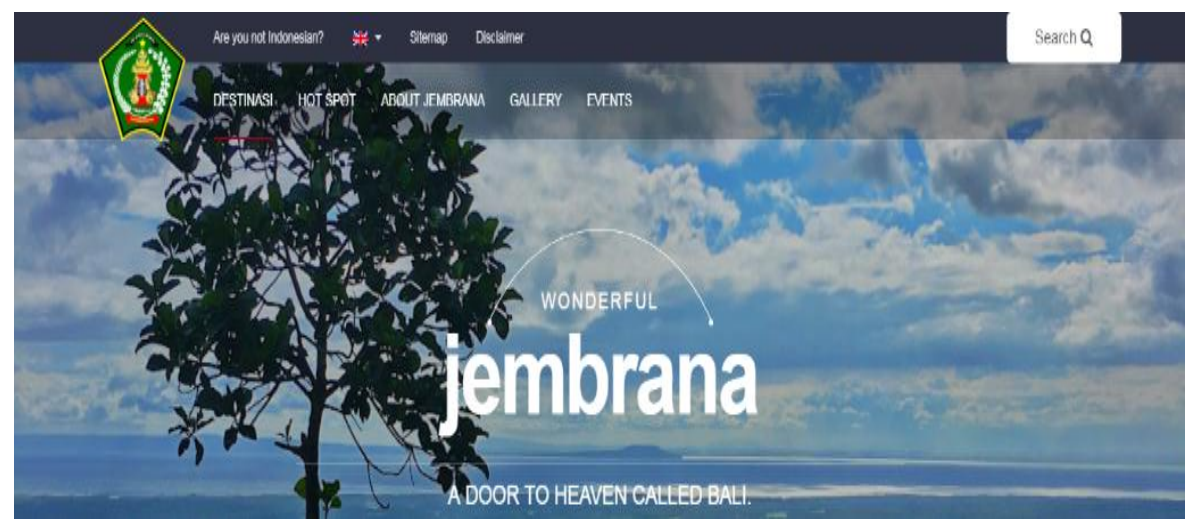

Gambar 4. Situs Website Dinas Pariwisata Kabupaten Jembrana 
Perbedaan yang ada pada kedua situs website kedua kabupaten, yaitu pada situs website milik Dinas Pariwisata Kabupaten Buleleng terdapat menu pariwisata dan submenu berupa jenis wisata yang ditawarkan, dalam hal ini wisata air terjun terdapat pada menu wisata alam yang didalamnya telah terdapat nama objek wisata alam diantaranya air terjun, bukit, dan pantai. Sedangkan untuk situs website milik Dinas Pariwisata Kabupaten Jembrana pada menu utama langsung disajikan destinasi wisata pada daerah tersebut dengan pemecahan menu dengan menggunakan nama kecamatan di Kabupaten Jembrana, seperti Melaya, Negara, Jembrana, Mendoyo dan Pekutatan District. Dalam menu nama kecamatan terdapat submenu yang didalamnya terdapat pembagian jenis objek wisata (sama seperti website milik Dinas Pariwisata Kabupaten Buleleng). Objek wisata air terjun terdapat pada menu nature. Didalam menu wisata air terjun pada setiap situs website memiliki kesamaan yaitu terdapat penjelasan mengenai penamaan wisata tersebut, lokasi dan foto yang ada sesuai dengan kenyataan.

Dengan contoh dua situs website Dinas Pariwisata milik Kabupaten Buleleng dan Jembrana dapat membantu situs website Dinas Pariwisata pada kabupaten lain untuk memberikan informasi megenai objek wisata yang dimiliki salah satunya objek wisata air terjun. Maka perancangan sistem informasi wisata air terjun disetiap kabupaten di Bali dapat menggunakan konsep mengikuti perkembangan teknologi saat penyajian yang ditawarkan bersifat global, real time, dapat mempermudah dan tepat dalam memberikan sebuah informasi terbaru. Dalam pengembangan sistem informasi pada situs website diharapkan Dinas Pariwisata dapat memaksimalkan kembali kinerjanya dalam mempromosikan objek wisata air terjun yang ada. Beberapa situs website Dinas Pariwisata yang hingga saat ini tidak memiliki informasi apapun, terdapat pada situs website Dinas Pariwisata Kabupaten Badung, 
Kabupaten Bangli, Kabupaten Gianyar dan Kabupaten Tabanan. Salah satu Dinas Pariwisata yang tidak memiliki situs website yaitu pada Kabupaten Klungkung, disini dapat terlihat sangat kurang maksimalnya Dinas Pariwisata memberikan informasi mengenai objek wisata, kegiatan maupun hal lain yang menyangkut kinerja kepemerintahaannya. Dengan diterapkannya pengembangan Sistem Informasi Wisata Air Terjun pada setiap kabupaten di Bali dapat memberikan manfaat dalam mengenalkan wisata air terjun secara global baik pada masyarakat sekitar, maupun wisatawan yang berkunjung, sehingga dapat menjaga, melestarikan dan memajukan pemerintah kabupaten. Perkembangan ini selain memaksimalkan kinerja dinas terkait dan memajukan daerah tersebut dapat meningkatkan devisa pemerintah kabupaten.

\section{Simpulan dan Saran}

Dari pemaparan tentang peran teknologi informasi dalam menginformasikan data wisata air terjun di website Dinas Pariwisata setiap kabupaten di Bali, maka dapat penulis simpulkan ada tiga kabupaten yang telah memanfaatkan website untuk memperkenalkan tempat wisata yang ada di daerahnya termasuk wisata air terjun, yaitu Kabupaten Jembrana, Kabupaten Karangasem, dan Kabupaten Buleleng. Website Kabupaten Jembrana mengelompokkan informasi wisata sesuai dengan kecamatan yang ada di Jembrana. Website Karangasem mengelompokkan informasi wisata sesuai dengan jenis wisata, sedangkan Kabupaten Buleleng tidak mengelompokkan informasi di website namun memberikan secara menyeluruh tentang tempat wisata yang ada di kabupaten Buleleng.

Situs website Dinas Pariwisata setiap kabupaten di Bali yang hingga saat ini tidak memiliki informasi mengenai tempat wisata termasuk air terjun di daerahnya, yaitu situs website Dinas Pariwisata kabupaten Badung, Kabupaten Bangli, Kabupaten Gianyar dan Kabupaten Tabanan. 
Dan terdapat salah satu Dinas Pariwisata yang tidak memiliki situs website yaitu Kabupaten Klungkung. Disini dapat terlihat sangat kurang maksimalnya Dinas Pariwisata memberikan informasi mengenai objek wisata, kegiatan maupun hal lain yang menyangkut kinerja Dinas Pariwisata di setiap kabupaten di Bali.

Penulis menyarankan setiap kabupaten di Bali mengembangkan sistem informasi wisata air terjun dengan menggunakan konsep mengikuti perkembangan teknologi yaitu disajikan secara global yang biasanya disebut dengan website sehingga sistem informasi ini dapat lebih mudah, dapat diakses secara global dan real time. Dengan adanya pengembangan sistem informasi wisata air terjun pada setiap kabupaten di Bali dapat memberikan manfaat dalam mengenalkan wisata air terjun kepada masyarakat sekitar, maupun wisatawan, sehingga dapat menjaga, melestarikan dan memajukan pemerintah di bidang pariwisata dalam meningkatkan devisa.

Selanjutnya, diharapkan dapat bekerjasama dengan situs website milik swasta yang memiliki data objek wisata lain lebih banyak dan terbaru. Dalam situs website dapat ditambahkan pengaduan permasalahan yang dapat diakses secara online sehingga mempermudah proses pengajuan pengaduannya. Diharapkan instansi pemerintah terutama pada Dinas Pariwisata kabupaten untuk lebih aktif kembali dalam memberikan informasi dan mencari objek wisata lain yang dapat diperkenalkan secara global untuk memajukan daerah tersebut. 


\section{Daftar Pustaka}

[A] Laudon, Traver. 2004. Internet and Website: Informatio. Technology, Society. New Jersey: Addision Wesley.

[B] Hakim. 2009. Kegunaan Sitemap. GRAMEDIA: Klaten.

[C] Sutarman. 2003. Membangun Aplikasi Web Dengan PHP dan MySQL. Yogyakarta: Penerbit Graha Ilmu.

[D] Kadir, Abdul. 2003: Pengenalan Sistem Informasi. Yogyakarta: ANDI.

[E] Hakim. 2009. Kegunaan Sitemap. GRAMEDIA: Klaten.

[F] Jogiyanto. 2005. Analisis dan Desain Sistem Informasi: Pendekatan Terstruktur. Yogyakarta: Penerbit Andi.

[G] Noname. 2018. Pemerintah Kota Denpasar Dinas Pariwisata. (https://pariwisata.denpasarkota.go.id/). (diakses pada tanggal 25 April 2018).

[H] Noname. 2018. Dinas Pariwisata Pemerintah Kabupaten Tabanan. (https://dispar.tabanankab.go.id/). (diakses pada tanggal 25 April 2018).

[I] Noname. 2018. Dinas Pariwisata Pemerintah Kabupaten Buleleng. (https://dispar.bulelengkab.go.id/). (diakses pada tanggal 25 April 2018).

[J] Noname. 2018. Wonderful Jembrana. (https://wonderful.jembranakab. go.id/). (diakses pada tanggal 25 April 2018).

[K] Noname. 2018. Dinas Pariwisata Kabupaten Klungkung. (http://dispar.klungkungkab.go.id/). (diakses pada tanggal 25 April 2018). 
Ayu Aprilyana Kusuma Dewi

84 JOURNEY Volume 1 Nomor 2 Juni 2019 